\title{
Journal Club as a Platform for Paediatric Post-Graduate Medical Education: Lessons Learnt from a Tertiary Care Training Center in the United Kingdom
}

\author{
Dayasiri, M.B.K.C. ${ }^{1} \&$ Rao, S. ${ }^{2}$
}

\begin{abstract}
Background: Journal Club is an educational platform for junior doctors and is highly useful for sharing knowledge and practice, which in turn leads to improved care. However, this forum was infrequently held, poorly attended and given less priority and trainees had less interest according to a 2018 online survey at the Department of Paediatrics, John Radcliffe Hospital, Oxford.
\end{abstract}

Methods: Journal Club was conducted over one year with incorporation of new organisational measures. Trainees were invited to present had the ownership of the choice of article. Presenters were encouraged with formal written feedbacks for their e-portfolio. Junior doctors were guided but had their own choice for selecting themes. Each session was advertised by regular weekly emails to improve attendance. Resource articles were distributed in advance to promote discussion and peer learning. An online survey was conducted to assess the impact of the changes after thirteen months following these interventions.

Results: Fifty weekly Journal Clubs were held over fourteen months. Fifty five junior and senior trainees presented with presentation rate being $93 \%$. Forty trainees and consultants responded to the online survey. Eighty seven percent were satisfied about session length. $100 \%$ believed the presented topics were relevant. Ninety six percent of responders believed that the Journal Club was at least somewhat relevant to their clinical practice. $100 \%$ believed that alert emails were useful. All responders believed that resource articles were at least somewhat helpful.

Conclusion: Provision of written feedback, regular and friendly reminders for participation and distribution of resources articles prior to the Journal Club meeting were associated with improved participation and overall satisfaction among both presenters and attendees.

Key words: Journal Club, Medical Education, Paediatrics

\section{Introduction}

Journal Club $s$ have been used as a platform for teaching academic medicine to both undergraduate and post-graduate trainees for more than fourteen decades and its inception by Sir William Osler in 1875 (Linzer, 1987; Gushing, 1926).

\footnotetext{
${ }^{1}$ Paediatric Clinical Fellow, Department of Paediatrics, Oxford University Hospitals NHS Foundation Trust, Oxford, United Kingdom.

${ }^{2}$ Consultant in Acute Paediatrics and Lead for Quality Improvement, Department of Paediatrics, Oxford University Hospitals NHS Foundation Trust, Oxford, United Kingdom.

Corresponding Author: Dr. Kavinda Dayasiri

Paediatric Clinical Fellow, Department of Paediatrics, Oxford University Hospitals NHS Foundation Trust, Oxford, United Kingdom.
}

DOI: http://doi.org/10.4038/seajme.v14i1.217
The practice of review of the latest medical research by academic colleagues based on Journal Club forums was first reported in 1889 at John Hopkins University (Sleeman et al., 1990). The Journal Club has since evolved to a great extent that it is recognized as an effective method of education in many medical schools and residency training programs. The important contributions of Journal Clubs to trainees' clinical practice include enhancement of critical appraisal skills, knowledge sharing skills, increasing the practice of evidence based medicine and regular review of up-to-date medical literature.

Randomized control studies have shown that Journal Club s over standard teaching improve

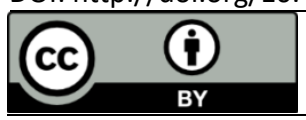

C SEAJME. This is an Open Access article distributed under the terms of the Creative Commons Attribution License (http://creativecommons.org/licenses/by/4.0/), which permits unrestricted use, distribution, and reproduction in any medium, provided the original author and source are credited 
reading skills and evidence searching skills of medical professionals (Linzer et al., 1988). Similarly, Journal Club $s$ were effective in putting evidence in to clinical practice, learning epidemiology and statistics and understanding strengths and limitations of study designs and findings (Liner et al., 1988). In order to meet these objectives, effective strategies are needed to be implemented in the organisation and conduct of Journal Clubs.

The current study has evaluated participant's satisfaction and perspectives for further improvement of departmental Journal Club following introduction of new organsational measures and thereafter, conduct of the Journal Club weekly for fourteen months.

\section{Objectives}

1. To improve knowledge sharing skills among junior doctors on evidence based paediatric care

2. To assess the impact of the Journal Club education forum and find ways to further improve the forum

\section{Methods}

The current study was performed at the Department of Paediatrics, John Radcliffe Hospital, which is part of Oxford University the Hospitals NHS Foundation Trust, United Kingdom and as part of quality improvement in medical education. Investigators of the study organised weekly Journal Club $s$ for fourteen months (from May 2018 to July 2019) to facilitate medical education and continuous professional development among trainees at different levels including Foundation grades, Specialty Paediatric training grades, Specialty and Associate Specialty (SAS) grades and General Practitioner training grades.

The investigators followed several methods to improve voluntary participation by presenters, enhance participation of the audience, provide constructive feedback and increase overall satisfaction about paediatric Journal Clubs. Trainees were invited to present and the trainee had the ownership of the choice of article. However, only voluntary participation was encouraged. Presenters were encouraged with formal written constructive feedbacks for their e-portfolio and also included a presentation certificate was included.

Junior doctors were guided by expert faculty members but had their own choice for selecting themes and articles. Each session was advertised by regular weekly emails to improve attendance. Topics were advertised in the form of a research question as much as possible. Specific objectives were provided for some of these sessions 3 - 4 days prior via e-mail. Resource articles were distributed in advance to promote discussion and peer learning. Organisers ensured participation of an expert faculty member in each Journal Club session as much as possible. An online survey was conducted to assess the impact of the changes after fourteen months following these interventions

Over fourteen months, the aforementioned new organizational measures were incorporated to the departmental Journal Club and effectiveness of such interventions were assessed using an online participant survey over one month. Formal ethical clearance was not required for the study, however, institutional approval was granted by Quality Improvement Proposal Review board of the Oxford University Hospitals NHS Foundation Trust.

\section{Results}

Fifty weekly Journal Clubs were held over fourteen months (From May 2018 to July 2019). Fifty-five junior (specialty training 1-5) and senior (specialty training 6-8) paediatric trainees had presented in Journal Club forums. Ninety three percent of trainees were able to present as scheduled while the remaining seven percent could not present as scheduled due to training and clinical work related commitments. Median of attendance per session was 11 .

Presented themes were of trainees' choice in $100 \%$ of presentations and the common themes were related to paediatric respiratory medicine (10 sessions), quality improvement (8 sessions), paediatric emergencies (7 sessions) and paediatric infections (5 sessions). Figure 1 shows the themes of the Journal Clubs presented over the study period.

The majority of trainees who presented in the Journal Club sessions were in Specialty Training level 4 -8 (24 trainees). All presenters volunteered for their presentations. Figure 2 shows relative contributions at presenting in Journal Clubs based on the academic role.

Forty participants responded to the online survey (14 Paediatric trainees, 8 Foundation level trainees, 6 General Practitioner trainees, 8 Specialty doctors, and 4 Paediatric Consultants). 
The majority rated Journal Club at least satisfactory as a postgraduate medical education platform (excellent $-10,25 \%$, very good $-14,35 \%$, good $-2,5 \%$, poor $-0 \%$ ). The majority believed the one hour teaching time was about right $(34,85 \%)$ whilst 6 participants $(15 \%)$ believed the sessions were too long. Most participants believed the sessions were well-organised (extremely well-organised - 15,
$37.5 \%$, well organised $-14,35 \%$, somewhat organised $-10,25 \%$, not so organised -1 , $2.5 \%$ ). Nineteen responders believed the sessions were somewhat useful for their dayto-day clinical practice whilst 11 responders $(27.5 \%)$ and 10 responders $(25 \%)$ were of the opinion that they were either extremely useful or very useful respectively.

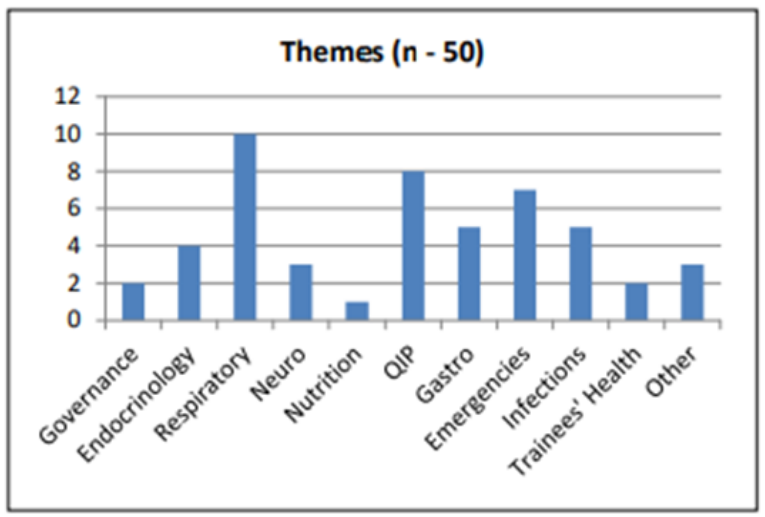

Figure 1: Themes of Journal Clubs presented over the study period (QIP - Quality Improvement Projects)

Pre-alert emails were distributed among all department members prior to all fifty Journal Club sessions mentioning details of presenter, topic and enclosing all resource materials. Fourteen responders $(35 \%)$ rated emails as extremely useful whilst $18(45 \%)$ rated as very useful. None rated them as 'not so useful'.

Resource materials including journal articles, protocols, and guidelines were sent to all department members in advance of all sessions. The majority were of the view that pre-session resource materials were helpful [extremely useful $-13,32.5 \%$, very useful -16 $(40 \%)$, somewhat useful - $9(22.5 \%)$, not so useful $-2(5 \%)$ ]. All participants reported that topics of Journal Club sessions were time relevant and relevant to the audience (extremely relevant $-10(25 \%)$, very relevant $10(25 \%)$, relevant $-20(50 \%)$, irrelevant -0 $(0 \%)]$.

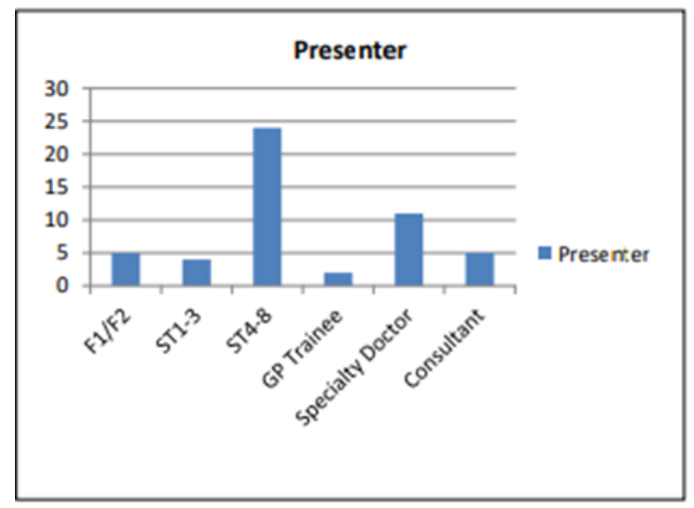

Figure 2: Relative contributions at presenting in Journal Clubs based on academic role (F1/F2 Foundation Level 1 \& 2, ST - Specialty Training Level, GP-General Practitioner). 
The majority of responders were of the opinion that the Journal Club was important as a platform for improving critical appraisal skills and keeping up-to-date with new developments in paediatric practice $(34,85 \%)$.

Analysis of written feedback by all participants revealed that the Journal Club was very useful specially for junior Paediatric trainees and resource materials were thought provoking. It was also suggested by the majority that a departmental Journal Club should also encourage participation and presentation by other departments such as Neonatology, Paediatric Intensive Care and Emergency Medicine. Several respondents proposed introduction of a structured critical appraisal instrument which can be distributed along with resource material via e-mail. It was also suggested to enhance participation by the faculty and arrange a refreshment rota that would encourage participation.

\section{Discussion}

One of the most important steps in establishing an effective and successful Journal Club series is the appointment of a designated leader who has continuing interest in resident education and motivation to organise Journal Clubs (Heiligman et al., 1987). The organisers of the Journal Club series in current study included the departmental quality improvement lead and a senior Paediatric trainee. It is equally important to set specific objectives and the objectives are agreed upon by the participants (Mazal et al., 2014; Hohmann et al., 2016; Hartzell et al., 2009; Alguire et al., 1988). All trainees who presented in the current Journal Club series were offered guidance and support in selecting topics and preparing presentation slides by faculty and senior paediatric trainees. Availability of guidance and support from mentors and senior colleagues are crucial in delivering a productive output from the Journal Club so that it can also meet core objectives (Greene et al., 2000; Al Achkar et al., 2016).

Most respondents in the current study were of the view that the Journal Club was important for them in improving critical appraisal skills and keeping up-to-date with paediatric practice. The observation is similar to the finding of a pervious study that assessed the impact of the Journal Club among post-graduate paediatric trainees (Valentini et al., 1997).

The Journal Club series in the current study focused more on improving critical evaluation skills of trainees. Most Journal Club sessions were based on one journal article and the methodology and findings were critically evaluated. However, there were several sessions that had a focus more on improving up-to-date knowledge and discussed reviews and several journal articles in one session (Markert et al., 1989).

Regular attendance by trainees is one important factor that affects the success rate of a Journal Club (Sidorov et al., 1995). Studies have reported that attendance could be improved by making it a requirement for trainees to complete their residency programs and incorporation of formal teaching (Valentini et al., 1997). However, in the current series, participation was voluntary and only original research was critically evaluated. Principles of relevant methodology, epidemiology and biostatistics relevant to the study were discussed during discussion time to improve efficiency and understanding (Linzer et al., 1987 ) by trainees. All sessions in the current Journal Club series were scheduled for Friday lunch time every week; pre-alert email reminders were sent to all members of the department; and resource articles were sent in advance. All sessions were held for one hour which was just right timing for most of the responders. These actions were planned to increase the interest of trainees in the Journal Club which is one very important factor (Heiligman et al., 1987) determining success rates. Scheduling at lunch time promotes participation of trainees (Sidorov et al., 1995) who would otherwise be busy with commitments to patient care. Furthermore, inconsistent scheduling and long duration sessions can negatively impact attendance and the success rate of Journal Clubs (Valentini et al., 1997).

Journal Clubs in literature show high variability in frequency they were held and duration of the sessions (Liner et al., 1986; Van Derwood et al., 1991). There is no agreement on optimum frequency of Journal Club meetings (Gottlieb et al., 2018). In the current series, the organisers ensured that the Journal Club meetings were organised once per week so that trainees will get maximal opportunity to present and participate during their 4-6 month long Paediatric rotation. What would be more effective would be to have Journal Clubs at predicted intervals so that participants can anticipate and schedule time effectively (Steele-Moses et al., 2009).

All presenters in the current Journal Club series were provided with written constructive 
feedback that could be incorporated to their eportfolios. Provision of constructive feedback has been shown to improve critical appraisal skills (Seelig et al., 1991). One of the important suggestions by participants of this survey was development of a structured critical appraisal instrument. Incorporation of critical appraisal instruments have been shown to enhance satisfaction of participants, promote educational value and productive discussion without increasing workload (Burstein et al., 1996; Honey et al., 2011).

All data and resource materials presented in current study were stored the future reference by trainees. This has been a feature in other studies to improve success rates of Journal Club (Deenadayalan et al., 2008). Provision of incentives has also been observed as one factor which encourages participation (Bhattacharya, 2017). This could be resource material, continuous professional development points or even refreshments.

The current study has a few limitations over validity of its findings. Firstly, trainees at Oxford's Children's Hospital keep rotating their paediatric appointments every 4-6 months. Therefore, the responses were not based on their experience during the whole duration during which weekly Journal Clubs were held. However, only trainees who had at least 4 months experience with the departmental Journal Club were invited to participate in the study. Due to same reason, it was not possible to evaluate effectiveness of newly introduced organsational measures in the interventional study design. Satisfaction surveys are one of the best methods to assess effectiveness of Journal Clubs and enable periodic refinements to increase quality (Valentini et al., 1997).

\section{Conclusion}

Provision of written feedback, regular and friendly reminders for participation, and distribution of resource articles one week prior to Journal Club meetings were associated with improved participation and overall satisfaction among both presenters and the audience.

\section{Conflicts of interests}

The authors declare no conflict of interest.

\section{References}

Al Achkar, M. (2016) Redesigning Journal Club in Residency. Advances in Medical Education and Practice, 7, pp. 317.
Alguire, P. C. (1998). A Review of Journal Clubs in Postgraduate Medical Education. Journal of General Internal Medicine, 13, 5, pp. 347-353.

Bhattacharya, S. (2017) Journal Club and PostGraduate Medical Education. Indian Journal of Plastic Surgery, 50, 03, pp. 302-305.

Burstein, J. L., Hollander, J. E., \& Barlas, D. (1996). Enhancing the Value of Journal Club: Use of a Structured Review Instrument. The American Journal of Emergency Medicine, 14, 6, pp. 561563.

Deenadayalan, Y., Grimmer-Somers, K., Prior, M., \& Kumar, S. (2008). How to Run an Effective Journal Club: A Systematic Review. Journal of Evaluation in Clinical Practice, 14, 5, pp. 898911.

Gottlieb, M., King, A., Byyny, R., Parsons, M., \& Bailitz, J. (2018). Journal Club in Residency Education: An Evidence-based Guide to Best Practices from the Council of Emergency Medicine Residency Directors. The Western Journal of Emergency Medicine, 19, 4, pp. 746755.

Greene, W. B. (2000). The Role of Journal Clubs in Orthopaedic Surgery Residency Programs. Clinical Orthopaedics and Related Research, 373, pp. 304-310.

Gushing, H. (1926). The Llife of Sir William Osler, New York: Oxford University Press, 1, pp. 132133.

Hartzell, J. D., Veerappan, G. R., Posley, K., Shumway, N. M., \& Durning, S. J. (2009). Resident Run Journal Club: A Model Based on the Adult Learning Theory. Medical Teacher, 31, 4, pp. e156-e161.

Heiligman, R.M. \& Wollitzer, A.O. (1987) A Survey of Journal Clubs in US Family Practice Residencies. Academic Medicine, 62, 11, pp.928-931.

Hohmann, E., \& Tetsworth, K. (2016). Teaching residents: critical appraisal of the literature using a Journal Club format. Postgraduate medical journal, 92, 1093, pp. 645-648.

Honey, C.P. \& Baker, J.A. (2011) Exploring the Impact of Journal Clubs: A Systematic Review. Nurse Education Today, 31, 8, pp. 825-831.

Linzer, M., Mercando, A., \& Hupart, K. H. (1986). Role of a Medical Journal Club in Residency Training. Journal of Medical Education, 61, 6, pp. 471-473.

Linzer, M. (1987) The Journal Club and Medical Education: Over One Hundred Years of Unrecorded History. Postgraduate Medical Journal, 63, 740, pp. 475-478. 
Linzer, M., DeLong, E. R., \& Hupart, K. H. (1987). A Comparison of Two Formats for Teaching Critical Reading Skills in a Medical Journal Club. Journal of Medical Education, 62, 8, pp. 690-692.

Linzer, M., Brown, J.T., Frazier, L.M., DeLong, E.R., \& Siegel, W.C. (1988). Impact of a Medical Journal Club on House-staff Reading Habits, Knowledge, and Critical Appraisal Skills. A Randomized Control Trial, JAMA, 260, pp. 25372541.

Markert, R.J. (1989) A Research Methods and Statistics Journal Club for Residents. Academic Medicine: Journal of the Association of American Medical Colleges, 64, 4, pp. 223-224.

Mazal, J. \& Truluck, C. (2014) Organizing and Leading a Journal Club. Radiologic Technology, 85,5 , pp. 549-553.

Seelig, C. B. (1991). Affecting Residents' Literature Reading Attitudes, Behaviors, and Knowledge through a Journal Club Intervention. Journal of General Internal Medicine, 6, 4, pp. 330-334.
Sidorov, J. (1995). How are Internal Medicine Residency Journal Clubs Organized, and What Makes Them Successful? Archives of Internal Medicine, 155, 11, pp. 1193-1197.

Sleeman, W. (1990) Dr. Osler and the Book and Journal Club of the Medical and Chirurgical Faculty of Maryland. Maryland Medical Journal (Baltimore, Md.: 1985), 39, 12, pp. 1111.

Steele-Moses, S. K. (2009). Developing a Journal Club at Your Institution. Clinical Journal of Oncology Nursing, 13, 1, pp. 109-112.

Valentini, R. P., \& Daniels, S. R. (1997). The Journal Club. Postgraduate Medical Journal, 73, 856, pp. 81-85.

Van Derwood, J. G., Tietze, P. E., \& Nagy, M. C. (1991). Journal Clubs in Family Practice Residency Programs in the Southeast. Southern, Medical Journal, 84, 4, pp. 483-487. 